\title{
Determination of Optimal Dose of Arginine Vasopressin in Hemorrhagic Shock in Dogs
}

\author{
Jong-Hyun YOO $^{1)}$, Chul PARK ${ }^{2)}$, Dae-Hyun HAHM ${ }^{3,4)}$, Hye-Jung LEE ${ }^{3,4)}$ and Hee-Myung PARK ${ }^{2) *}$ \\ ${ }^{1)}$ BK21 Program of Integrative Network Systems for Veterinarians in Basic Science, Industrial Animals and Preventive Medicines and \\ ${ }^{2)}$ Department of Veterinary Internal Medicine, College of Veterinary Medicine, Konkuk University, \#1 Hwayang-dong, Gwangjin-gu, \\ Seoul 143-701, ${ }^{3)}$ Acupuncture \& Meridian Science Research Center and ${ }^{4)}$ Institute of Oriental Medicine, College of Korean Medicine, \\ Kyung-Hee University, Hoigi-dong, Dongdamoon-gu, Seoul 130-701, South Korea
}

(Received 5 December 2006/Accepted 14 February 2007)

ABSTRACT. The hemodynamic effects of vasopressin of high/low doses on dogs were investigated using experimentally induced hemor-
rhagic shock model. Experimental groups were categorized according to administered doses of vasopressin $(0.1,0.4$ and $1.6 \mathrm{IU} / \mathrm{kg})$ and
hemodynamic parameters were measured before and after the graded-dose administration of vasopressin. Administration of high- and
middle-dose vasopressin $(0.4 \mathrm{and} 1.6 \mathrm{IU} / \mathrm{kg})$ showed superior increase in blood pressure and systemic vascular resistance, compared with
those of low-dose one $(0.1 \mathrm{IU} / \mathrm{kg})$. Results of systolic arterial pressure and mean arterial pressure in $1.6 \mathrm{IU} / \mathrm{kg}$-administered group
revealed lower efficacy than that in $0.4 \mathrm{IU} / \mathrm{kg}$ group in spite of administration of higher dose. This study demonstrates that $0.4 \mathrm{IU} / \mathrm{kg}$
of vasopressin can be used as the most effective dose for improving hemodynamic condition in the decompensatory phase of hemorrhagic
shock in dogs. KEY WORDS: hemorrhagic shock, optimal dose, vasopressin.

Rapid vasoconstriction agents (vasoconstrictors) are frequently administered with fluid and inotropics to resuscitate dogs with decompensatory hemorrhagic shock [3]. The exogenous vasopressin in vasodilatory shock tends to produce remarkable vasoactive effects because the endogenous plasma vasopressin concentration is inappropriately lower due to impaired baroreflex-mediated secretion [21] and enhancement of sensitivity to vasoconstriction with unknown reasons [13]. In addition to inappropriate low plasma concentrations of vasopressin, the effectiveness of low doses of exogenous vasopressin in restoring blood pressure in irreversible shock further supports "a syndrome of hormone deficiency" as a pathogenesis of irreversible hypovolemic shock, which potentially make vasopressin therapeutic consideration [20].

However, some adverse effects of vasopressin have been also reported in controlling vasodilatory shocks $[5,12,18]$. Vasopressin administration could impair blood flow to tissues due to its remarkable vasoconstrictive effect on peripheral blood vessels. Especially, the vasopressin at high dose $(7.5-10 \mathrm{ng} / \mathrm{kg} / \mathrm{min})$ could induces ischemic injuries in the gastrointestinal tract, skin, myocardium, and liver in patients of catecholamine-resistant shock and the fixed rate of low-dose administration, therefore, was recommended in a literature [16]. Thus, safety margins of exogenous vasopressin for hypovolemic shock should be well documented prior to clinical trial. Unfortunately, knowledge remains limited about appropriate dosage of vasopressin for dogs

\footnotetext{
* Correspondence to: Park, H.-M., Department of Veterinary Internal Medicine, College of Veterinary Medicine, Konkuk University, \# 1 Hwayang-dong, Gwangjin-gu, Seoul, 143-701, South Korea.

e-mail: parkhee@konkuk.ac.kr
}

with decompensatory hemorrhagic shock.

Appropriate dosage of vasopressin in pigs has been reported to range from 0.2 to $0.8 \mathrm{IU} / \mathrm{kg}[9,14]$. Hemodynamic effects of vasopressin in a different dosage manner have been already studied in rabbits [10] and pigs [14], but not yet in dogs. Therefore, the hemodynamic changes by different dosage of arginine vasopressin, in the present study, were investigated in dogs with experimentally induced hemorrhagic shock, which identify an optimal dosage of vasopressin for restoring poor hemodynamics.

Six healthy mature mongrel dogs weighing between 8.3 and $9.5 \mathrm{~kg}$ were used in this study. They ranged in age between 2 and 4 yrs. Caring and treating all dogs used in this study strictly conformed to the standard protocols established by the Seoul National University for Accreditation of Laboratory Animal Care.

Anesthesia, induction of hemorrhagic shock, femoral catheterization, Swan-Ganz catheterization, and hemodynamic measurements were performed as described previously [24]. The baseline hemodynamic parameters were measured at $30 \mathrm{~min}$ after mean arterial pressure (MAP) reached to $60 \mathrm{mmHg}$ by exsanguination. These parameters included systolic arterial pressure (SAP), diastolic arterial pressure (DAP), central venous pressure (CVP), pulmonary capillary wedge pressure (PCWP), and cardiac output $(\mathrm{CO})$. After the completion of measurement, vasopressin ([ $\left.\mathrm{Arg}^{8}\right]$ Vasopressin; Sigma-Aldrich, U.S.A.) diluted with saline to $1 \mathrm{U} / \mathrm{m} l$ was intravenously administered by bolus with 3 different dosages, low $(0.1 \mathrm{IU} / \mathrm{kg})$, middle $(0.4 \mathrm{IU} / \mathrm{kg})$, and high $(1.6 \mathrm{IU} / \mathrm{kg})$ doses in consecutive order, which is similar protocol reported by Guo G.B. et al. [10] In brief, SAP and DAP were measured at 1, 2, 3, 4, 5, 10, 15, 20, and $25 \mathrm{~min}$ after the first infusion of vasopressin $(0.1 \mathrm{IU} / \mathrm{kg})$. Other 
hemodynamic parameters were determined at 5, 10, 15, 20, and $25 \mathrm{~min}$ after the infusion of vasopressin. The second vasopressin infusion $(0.4 \mathrm{IU} / \mathrm{kg})$ was always conducted at the 30-40 min after full recovery from the first vasopressin infusion (after MAP was returned to the baseline). The third vasopressin infusion $(1.6 \mathrm{IU} / \mathrm{kg}$ ) was performed in the same way after full recovery from the second vasopressin infusion.

All values are presented as mean \pm SD. Data were grouped by each dosage of vasopressin $(0.1 \mathrm{IU} / \mathrm{kg}, 0.4 \mathrm{IU} /$ $\mathrm{kg}$, and $1.6 \mathrm{IU} / \mathrm{kg}$ ). One-way ANOVA followed by Duncan's multiple range test was used to compare the hemodynamic changes by infusion of each dose of vasopressin between three groups.

The blood pressure and systemic vascular resistance (SVR) changes in the course of time are shown in Table 1. SAP increased in both 0.4 and $1.6 \mathrm{IU} / \mathrm{kg}$ concentrations at 5 $\mathrm{min}$. However, $1.6 \mathrm{IU} / \mathrm{kg}$ group showed the significant decrease of SAP at 15 and $20 \min (p<0.05)$, whereas at the same time 0.1 and $0.4 \mathrm{IU} / \mathrm{kg}$ groups exhibited the constantly increased pattern in SAP. Middle- and high-dose vasopressin group (0.4 and $1.6 \mathrm{IU} / \mathrm{kg}$ group) showed markedly increased DAP at 5 min compared with low-dose vasopressin ( $0.1 \mathrm{IU} / \mathrm{kg}$ group), but there was no statistically significant difference among all groups after $10 \mathrm{~min}$. The highest maximal SVR was reached at $5 \mathrm{~min}$ after vasopressin infusion in 0.4 and $1.6 \mathrm{IU} / \mathrm{kg}$ group and steeply returned to baseline value with time.

The time course of MAP for the first 5 min after infusion of different dose of vasopressin is plotted in Fig. 1. Marked increase in MAP were noted in 0.4 and $1.6 \mathrm{IU} / \mathrm{kg}$ groups than in $0.1 \mathrm{IU} / \mathrm{kg}$ group $(\mathrm{p}<0.05)$. The dose of $1.6 \mathrm{IU} / \mathrm{kg}$ was found to be less potent in elevating MAP than that of $0.4 \mathrm{IU} / \mathrm{kg}$ despite the higher dosage of administration. CI and PCWP values were not different among all groups in all tested time points (Table 2).

Table 1. Changes in systolic (SAP), diastolic arterial pressure (DAP), and systemic resistance index (SVRI) after vasopressin with different doses (Mean $\pm \mathrm{SD})$

\begin{tabular}{|c|c|c|c|c|c|c|c|}
\hline \multirow{2}{*}{$\begin{array}{c}\text { Variable } \\
\text { (Unit) }\end{array}$} & \multirow[b]{2}{*}{ Dose } & \multirow[b]{2}{*}{ Baseline* } & \multicolumn{5}{|c|}{ Time after vasopressin administration } \\
\hline & & & $5 \min ^{\dagger}$ & $10 \mathrm{~min}$ & $15 \mathrm{~min}$ & $20 \mathrm{~min}$ & $25 \mathrm{~min}$ \\
\hline \multirow{3}{*}{$(\mathrm{mmHg})$} & $0.1 \mathrm{IU} / \mathrm{kg}$ & $95.2 \pm 5.4$ & $104.2 \pm 4.8^{\mathrm{a})}$ & $100.3 \pm 3.9$ & $106.5 \pm 4.1^{\mathrm{a})}$ & $109.2 \pm 3.7^{\mathrm{a})}$ & $109.7 \pm 5.0$ \\
\hline & $0.4 \mathrm{IU} / \mathrm{kg}$ & $93.8 \pm 5.4$ & $113.0 \pm 3.7^{\mathrm{b})}$ & $101.0 \pm 2.7$ & $107.5 \pm 4.2^{\mathrm{a})}$ & $107.5 \pm 4.7^{\mathrm{a})}$ & $109.5 \pm 5.4$ \\
\hline & $1.6 \mathrm{IU} / \mathrm{kg}$ & $94.2 \pm 6.3$ & $117.3 \pm 3.7^{\mathrm{b})}$ & $100.5 \pm 3.7$ & $97.5 \pm 3.9^{\mathrm{b})}$ & $101.7 \pm 5.4^{\mathrm{b})}$ & $104.2 \pm 3.8$ \\
\hline \multirow{3}{*}{$\begin{array}{c}\text { DAP } \\
(\mathrm{mmHg})\end{array}$} & $0.1 \mathrm{IU} / \mathrm{kg}$ & $48.7 \pm 1.5$ & $57.2 \pm 6.7^{\mathrm{a})}$ & $52.7 \pm 4.3$ & $55.7 \pm 3.3$ & $57.0 \pm 1.7$ & $56.3 \pm 1.5$ \\
\hline & $0.4 \mathrm{IU} / \mathrm{kg}$ & $48.5 \pm 3.6$ & $64.8 \pm 2.8^{\mathrm{b})}$ & $53.0 \pm 3.6$ & $55.5 \pm 4.2$ & $55.0 \pm 4.3$ & $55.5 \pm 4.7$ \\
\hline & $1.6 \mathrm{IU} / \mathrm{kg}$ & $47.8 \pm 2.6$ & $64.8 \pm 3.8^{\mathrm{b})}$ & $53.8 \pm 3.8$ & $51.5 \pm 3.3$ & $53.2 \pm 3.5$ & $55.2 \pm 3.4$ \\
\hline \multirow{3}{*}{$\begin{array}{c}\text { SVRI } \\
\left(\mathrm{dyn} \bullet \mathrm{s} \cdot \mathrm{m}^{2} / \mathrm{cm}^{5}\right)\end{array}$} & $0.1 \mathrm{IU} / \mathrm{kg}$ & $2359 \pm 150$ & $2643 \pm 294^{\mathrm{a})}$ & $2427 \pm 183$ & $2538 \pm 272$ & $2518 \pm 256$ & $2358 \pm 309$ \\
\hline & $0.4 \mathrm{IU} / \mathrm{kg}$ & $2276 \pm 378$ & $3112 \pm 292^{\mathrm{b})}$ & $2535 \pm 193$ & $2348 \pm 295$ & $2331 \pm 149$ & $2395 \pm 214$ \\
\hline & $1.6 \mathrm{IU} / \mathrm{kg}$ & $2241 \pm 160$ & $3138 \pm 305^{\mathrm{b})}$ & $2548 \pm 171$ & $2411 \pm 229$ & $2464 \pm 299$ & $2501 \pm 402$ \\
\hline
\end{tabular}

* Completion of hemorrhagic shock. $\dagger$ min: minutes.

$\mathrm{a}, \mathrm{b})$ Values with different superscript letter are significantly different between different doses at a time $(\mathrm{p}<0.05)$.

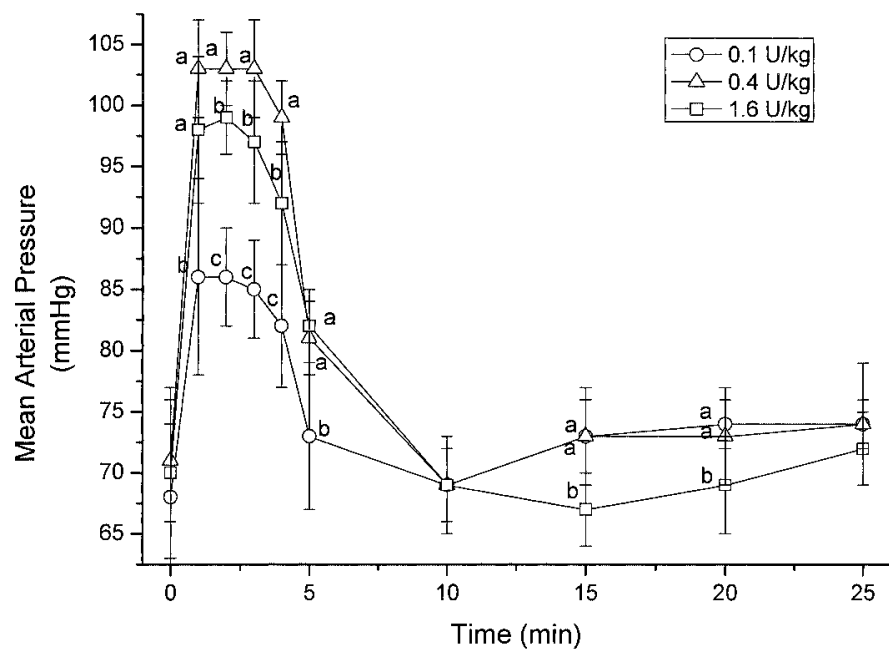

Fig. 1. Mean arterial pressure (MAP) after administration of vasopressin in hemorrhagic shock in dogs. a, b, c Value with different superscript letters are significantly different between different doses at a time $(\mathrm{p}<0.05)$. 
Table 2. Cardiac index $(\mathrm{CI} ; \mathrm{ml} / \mathrm{min} / \mathrm{kg})$ and pulmonary capillary wedge pressure (PCWP; $\mathrm{mmHg}$ ) before and after vasopressin administration with different doses $($ Mean $\pm \mathrm{SD})$

\begin{tabular}{|c|c|c|c|c|c|c|c|}
\hline \multirow{2}{*}{ Dose } & & \multirow{2}{*}{ Baseline* } & \multicolumn{5}{|c|}{ Time after vasopressin administration } \\
\hline & & & $5 \min ^{\dagger}$ & $10 \mathrm{~min}$ & $15 \mathrm{~min}$ & $20 \mathrm{~min}$ & $25 \mathrm{~min}$ \\
\hline \multirow{2}{*}{$0.1 \mathrm{IU} / \mathrm{kg}$} & $\mathrm{CI}$ & $2.27 \pm 0.10$ & $2.20 \pm 0.19$ & $2.27 \pm 0.18$ & $2.33 \pm 0.21$ & $2.44 \pm 0.21$ & $2.61 \pm 0.31$ \\
\hline & PCWP & $3.33 \pm 1.51$ & $3.67 \pm 1.37$ & $3.33 \pm 1.21$ & $3.17 \pm 0.75$ & $3.50 \pm 0.84$ & $3.83 \pm 0.98$ \\
\hline \multirow{2}{*}{$0.4 \mathrm{IU} / \mathrm{kg}$} & CI & $2.35 \pm 0.38$ & $2.09 \pm 0.24$ & $2.25 \pm 0.25$ & $2.38 \pm 0.25$ & $2.48 \pm 0.30$ & $2.49 \pm 0.26$ \\
\hline & PCWP & $3.50 \pm 1.05$ & $3.67 \pm 0.82$ & $4.00 \pm 1.26$ & $4.00 \pm 0.63$ & $4.33 \pm 1.37$ & $4.17 \pm 1.33$ \\
\hline \multirow{2}{*}{$1.6 \mathrm{IU} / \mathrm{kg}$} & $\mathrm{CI}$ & $2.30 \pm 0.15$ & $2.11 \pm 0.20$ & $2.20 \pm 0.18$ & $2.26 \pm 0.26$ & $2.29 \pm 0.29$ & $2.35 \pm 0.36$ \\
\hline & PCWP & $4.00 \pm 0.89$ & $3.67 \pm 1.03$ & $3.33 \pm 0.52$ & $4.00 \pm 0.63$ & $4.17 \pm 0.75$ & $3.83 \pm 0.98$ \\
\hline
\end{tabular}

* Completion of hemorrhagic shock. $\dagger$ min: minutes.

Canine model of hypovolemic shock with controlled hemorrhage has been widely employed in medical and also in veterinary researches $[4,7,15,19]$. This study examined the hemodynamic characteristics according to graded high/ low dose of vasopressin after controlled hemorrhage in dogs. High- and middle- dose vasopressin administration produced marked increase in blood pressure and SVR when compared with those of low dose one. Interestingly, results of SAP and MAP in high-dose (1.6 IU/kg) vasopressin group showed lower efficacy than that in middle-dose $(0.4$ $\mathrm{IU} / \mathrm{kg}$ ) group in spite of administration of higher dose. The exact reason for the reduced efficacy of high-dose vasopressin is unclear in this study. Vasopressin has dosedependent vasoconstrictive action V1-receptor, but biphasic changes (vasoconstriction at lower doses and vasodilation at higher dose) after vasopressin infusion have been hypothesized [8]. Furthermore, a small study of intrabrachial administration vasopressin reported a dose-dependent biphasic change of forearm blood vessels in humans [2]. Sustained infusion was associated with preservation of the vasodilatory effect. Nitric oxide produced by vasopressin is proposed for vasodilation with high-dose vasopressin, while another study suggested the involvement of cGMP-related mechanism [22]. In addition, tachyphylaxis response and reduction in sympathetic nerve activity were observed with the higher doses of vasopressin [1]. It is likely that these results share similar mechanisms with our findings. Further studies may be required to comprehend the systemic biphasic effects of vasopressin in dogs.

Concerns are raised for the dose-dependent complications of vasopressin. Exogenous vasopressin can induce a marked pressor response to restore intravascular volume in septic shock [13]. Two literature reviewed that the risk of myocardial ischemia from low-dose vasopressin $(<0.04 \mathrm{U} /$ min) was minimal $[17,23]$. However in a retrospective study, there was increased mortality in patients with septic shock treated with vasopressin when compared to historical controls [11]. Even low-dose vasopressin (0.04 IU/min) acted as a potent vasoconstrictor of skin vessels in hypotension unresponsive to exogenous catecholamines [12]. Furthermore, bilirubin levels may increase during vasopressin infusion although a direct cause and pathomechanism have not been demonstrated [6]. In this study, no complications were found after the administration of vasopressin. This result might be due to the bolus administration method while previous reported complications were involved with constant infusion. However, further careful observation for any complications is needed in future clinical trials. Our study was limited to evaluate only the $0.1,0.4$, and $1.6 \mathrm{IU} /$ $\mathrm{kg}$ doses of vasopressin. Further studies on more detailed doses, such as $0.2,0.8$, and $1.2 \mathrm{IU} / \mathrm{kg}$, would provide information as to the more safe and effective dose of vasopressin for the hypovolemic shock in dogs.

In conclusion, vasopressin administration of $0.1 \mathrm{IU} / \mathrm{kg}$ dose was less vasoconstrictive effect and administration of $1.6 \mathrm{IU} / \mathrm{kg}$ vasopressin showed lower effect on the vascular system compared to $0.4 \mathrm{IU} / \mathrm{kg}$ vasopressin. Thus, the dose of $0.4 \mathrm{IU} / \mathrm{kg}$ was found to have moderate vasopressor effects on the decompensatory state of hemorrhagic shock in dogs.

ACKNOWLEDGEMENT. This work was supported by the SRC program of KOSEF (R11-2005-014).

\section{REFERENCES}

1. Abboud, F.M., Floras, J.S., Aylward, P.E., Guo, G.B., Gupta, B.N. and Schmid, P.G. 1990. Blood Vessels 27: 106-115.

2. Affolter, J.T., McKee, S.P., Helmy, A., Jones, C.R., Newby, D.E. and Webb, D.J. 2003. Clin. Pharmacol. Ther. 74: 9-16.

3. DiBartola SP. 2000. pp. 428-448. Fluid Theraphy in Small Animal Practice. 2nd ed. W.B. Saunders Company, Philadelphia.

4. Driessen, B., Jahr, J.S., Lurie, F. and Gunther, R.A. 2006. Vet. Anaesth. Analg. 33: 368-380.

5. Dunser, M.W., Mayr, A.J., Tur, A., Pajk, W., Barbara, F., Knotzer, H., Ulmer, H. and Hasibeder, W.R. 2003. Crit. Care Med. 31: 1394-1398.

6. Dunser, M.W., Mayr, A.J., Ulmer, H., Knotzer, H., Sumann, G., Pajk, W., Friesenecker, B. and Hasibeder, W.R. 2003. Circulation 107: 2313-2319.

7. Dyson, D.H. and Sinclair, M.D. 2006. Am. J. Vet. Res. 67: 1121-1130.

8. Foreman, B.W., Dai, X.Z. and Bache, R.J. 1991. Circ. Res. 69: $657-664$.

9. Gazmuri, R.J. and Ayoub, I.M. 2000. Crit. Care Med. 28: 1236-1238.

10. Guo, G.B., Schmid, P.G. and Abboud, F.M. 1986. Am. J. Physiol. 251: H644-H655.

11. Holmes, C.L., Walley, K.R., Chittock, D.R., Lehman, T. and Russell, J.A. 2001. Intensive Care Med. 27: 1416-1421.

12. Kahn, J.M., Kress, J.P. and Hall, J.B. 2002. Crit. Care Med. 
30: 1899-1901.

13. Landry, D.W., Levin, H.R., Gallant, E.M., Ashton, C. Jr., Seo, S., D’Alessandro, D., Oz, M.C. and Oliver, J.A. 1997. Circulation 95: 1122-1125.

14. Lindner, K.H., Prengel, A.W., Pfenninger, E.G., Lindner, I.M., Strohmenger, H.U., Georgieff, M. and Lurie, K.G. 1995. Circulation 91: 215-221.

15. Machado, C.G., Dyson, D.H. and Mathews, K.A. 2005. Am. J. Vet. Res. 66: 1227-1237.

16. Malay, M.B., Ashton, J.L., Dahl, K., Savage, E.B., Burchell, S.A., Ashton, R.C. Jr., Sciacca, R.R., Oliver, J.A. and Landry, D.W. 2004. Crit. Care Med. 32: 1327-1331.

17. Malay, M.B., Ashton, R.C. Jr., Landry, D.W. and Townsend, R.N. 1999. J. Trauma 47: 699-703.

18. Mogan, G.R., Wormser, G.P. and Gottfried, E.B. 1980. Am. J.
Gastroenterol. 73: 426-429.

19. Okrasinski, E.B., Krahwinkel, D.J. and Sanders, W.L. 1992. Vet. Surg. 21: 20-24.

20. Robin, J.K., Oliver, J.A. and Landry, D.W. 2003. J. Trauma 54: S149-S154.

21. Sharshar, T., Blanchard, A., Paillard, M., Raphael, J.C., Gajdos, P. and Annane, D. 2003. Crit. Care Med. 31: 1752-1758.

22. Suzuki, S., Takeshita, A., Imaizumi, T., Hirooka, Y., Yoshida, M., Ando, S. and Nakamura, M. 1989. J. Clin. Invest. 84: 427434.

23. Tsuneyoshi, I., Yamada, H., Kakihana, Y., Nakamura, M., Nakano, Y. and Boyle, W.A. 2001. Crit. Care Med. 29: 487493.

24. Yoo, J.H., Kim, M.S. and Park, H.M. 2006. J. Vet. Med. Sci. 68: 967-972. 